\title{
دور المصارف الإسلامية وثقافتها التظظيمية في تطوير المزيج التسويقي
}

$$
\begin{aligned}
& \text { د. آمال يوب } \\
& \text { العلوم الاقتصادية و العلوم التجارية } \\
& \text { و وعلوم التسبير } \\
& \text { جامعة } 20 \text { أوت } 1955 \text { - سكيكدة - }
\end{aligned}
$$

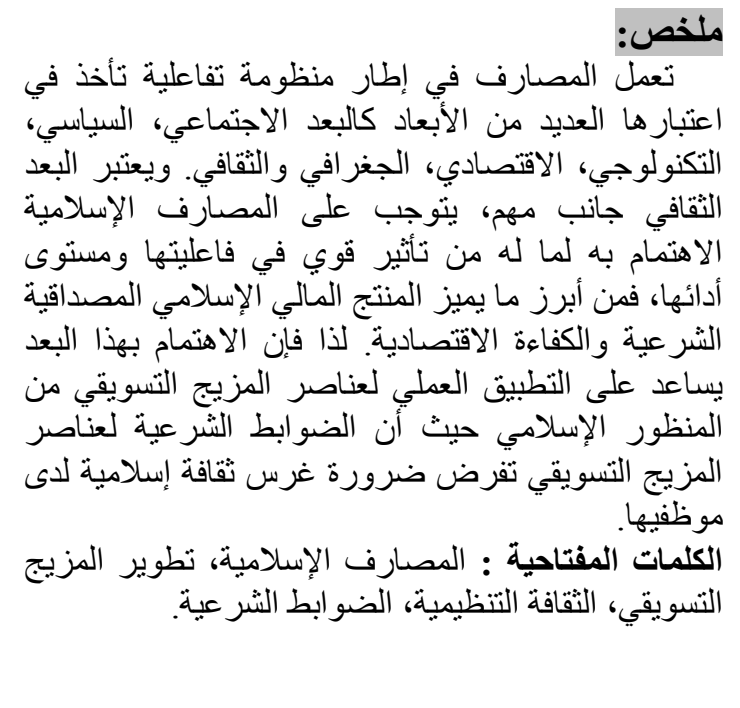

$$
\begin{aligned}
& \text { مقدّمة: } \\
& \text { ثقوم المصارف بدور } \\
& \text { كبير في اقتصاديات الدول من } \\
& \text { خلال أنشطتها ووظائفها التي التي } \\
& \text { تتعكس إيجابا أو سلبا على الثى } \\
& \text { تحقيق التتمية في تلك الدول، مما } \\
& \text { ينطلب من هذه المصارف أن أن } \\
& \text { تعمل على زيادة فعاليتها، وذلك } \\
& \text { من خلال الاهتمام بخدماتها زيالها } \\
& \text { والرفع من مستوى كفاءتها } \\
& \text { وتبسيط إجراءات سير عملها }
\end{aligned}
$$

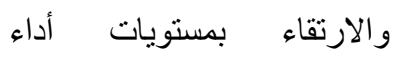

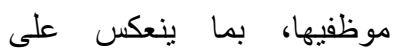

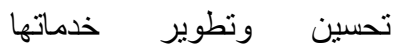

$$
\begin{aligned}
& \text { المصرفية وتحقيق احتياجات } \\
& \text { عملائها ورغباتهم. }
\end{aligned}
$$

\begin{abstract}
:
Learning banks as part of an interactive system that takes into account of many dimensions, like social remoteness, political, technological, economical, geographical and cultural. And it's considered an important aspect dimension, Islamic banks must interest in it because of its strong influence on efficiency and level of performance, it is the most prominent characteristic of the Islamic financial product credibility, legitimacy and economic efficiency. So the attention for this dimension helps the practical application of the elements of the mixed marketing from the Islamic perspective, where the legitimacy of the controls elements of the mixed marketing imposes the necessity of instilling Islamic culture among it's employee.
\end{abstract}

Key words: Islamic banks, development mixed marketing, organizational culture, legality controls. 


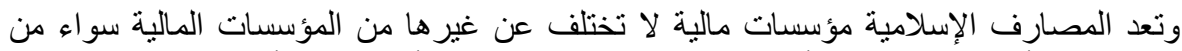

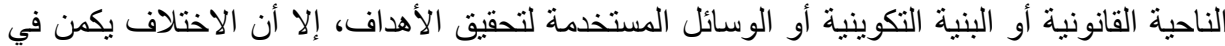

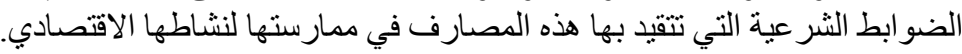

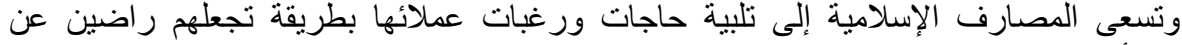
خذماتها أكثر من منافسيها، ولتحقيق ذلك فإنها تقوم بتصميم مزيج تسويقي يشبع احتياجاتهم ويتناسب مع التغير ات المستمرة التي تكتنسي تلأك الاحتياجات. مشكلة الاراسة : ماتئرة

تظهر مشكلة الدراسة في محاولة معرفة مدى مساهمة المصارف الإسلامية في تطوير المزيج الماريج

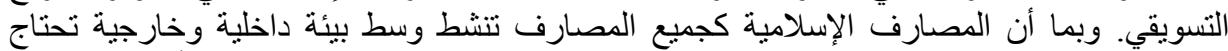

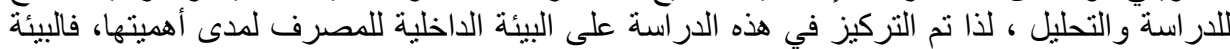

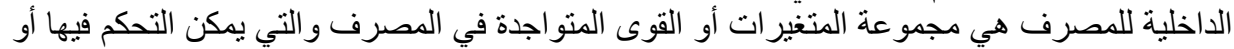

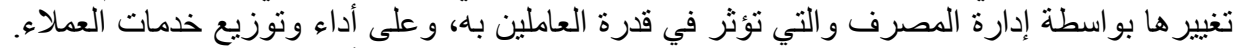

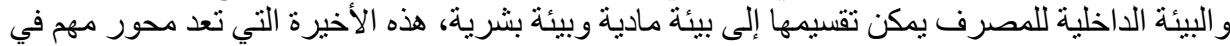

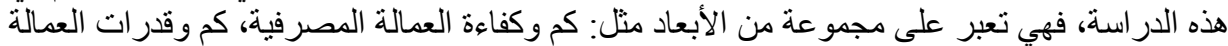

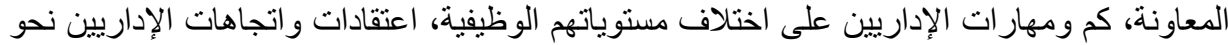

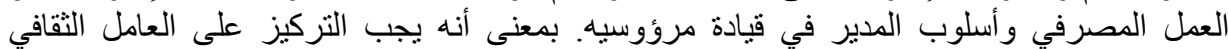

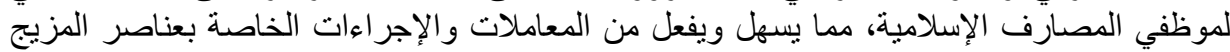

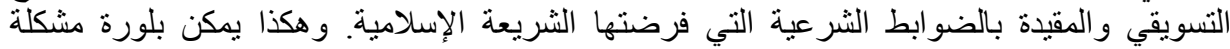
الدراسة في التساؤل الرئيسي التالي : التئي • ما مدى مساهمة الثقافة التنظيمية والضوابط الثرعية للمصارف الإسلامية في تطوير مزيجها التسويقي وقصد الإجابة على التساؤل الرئيسي لمشكلة الار اسة، نورد الأسئلة الفرعية التالية :

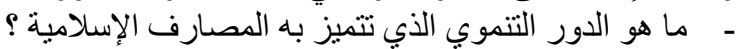

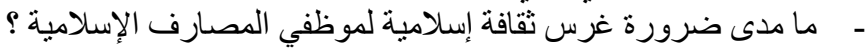

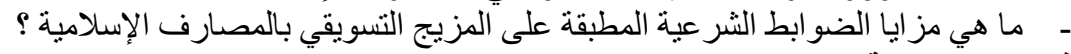

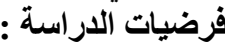

لتحقيق الهذف من الدراسة تم صياغة الفرضيات والتي تعتبر أكثر الإجابات احتمالا للأسئلة

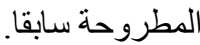

1- مساهمة المصارف الإسلامية في تحقيق تتمية اقتصادية و اجتماعية.

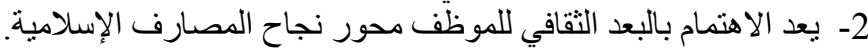
3- تساهم الضو ابط الثر عية المطبقة في المصنارف الإسلامية في تحقيق مز اليا على مزيجها التسويقي.

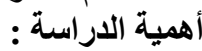
تنتبع أهمية هذه الدراسة من الداثة التي تميز المصارف الإسلامية من جهة وكذا التطورات

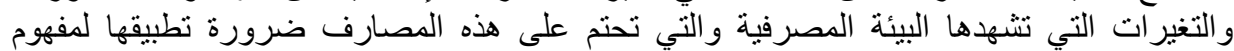
التسويق من أجلّ ضمان بقائها واستمر اريتها.

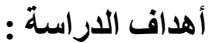

يتمثل الهذف الرئيسي لهذه الدراسة في محاولة توضيح دور المصارف الإسلامية لأجل تطوير

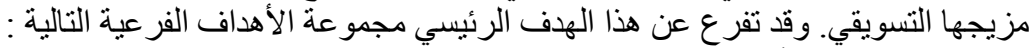

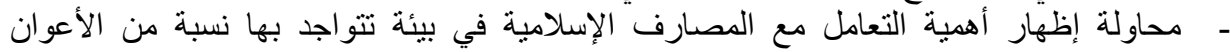
الاقتصاديين تتجنب التعامل بالربا. - توضيح مدى ضرورة غرس ثقافة إسلامية لموظفي المصارف الإسلامية. 
ـ - توضيح الضوابط الثرعية للمزيج التسويقي المصرفي الإسلامي، وما تحققه من مزايا مقارنة بالمصارف التقليدية.

أولا : المصارف الإسلامية

\section{1- 1 تعريف وخصائص المصارف الإسية الإسلامية :}

1.1 - 1.1 تعريف المصارف الإسلامية :

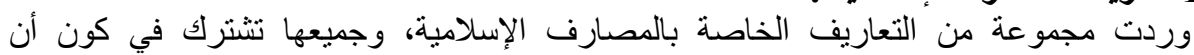

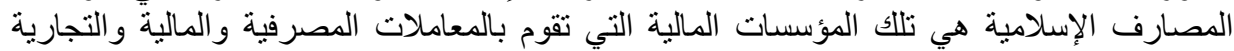

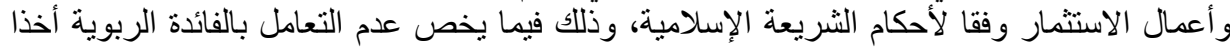

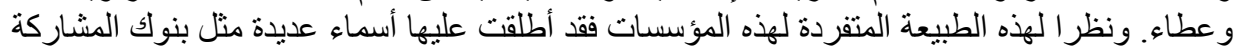

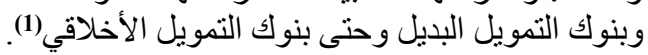
2.1 خصائص المصارف الإسلامية :

للمصرف الإسلامي خصائص تميزه عن غيره من الإسلمارف : الأخرى ومن أهم هذه الخصائص نذكر

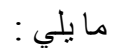

- ماستبعاد الفو ائد الربوية : إن أول ما يميز المصرف الإسلامي عن غيره من المصارف الرئام الربوية

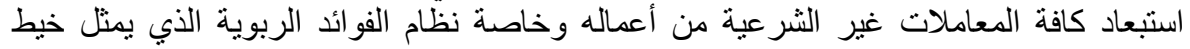

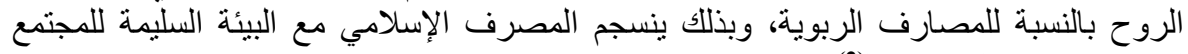
الإسلامي و لا يتناقض معهار (2). الأستثمار في المشاريع الحلال : يعتمد المصرف المارف الإسلامي في توظيف أمواله على الاستثمار

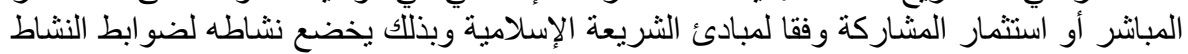

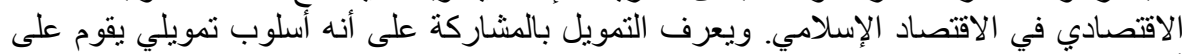

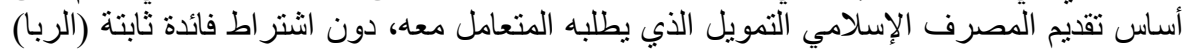

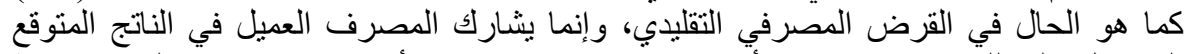

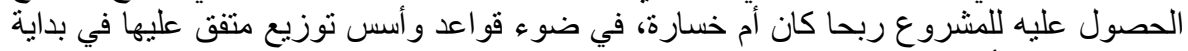

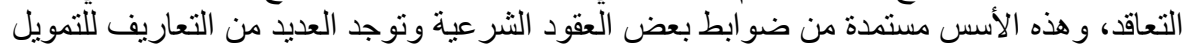

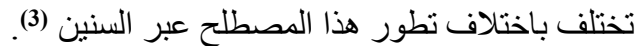

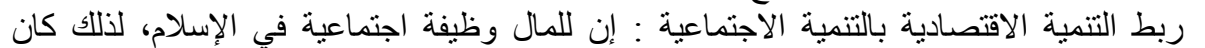

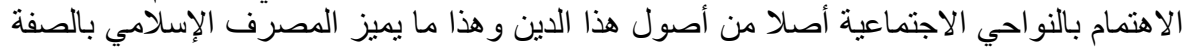

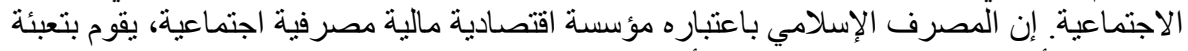

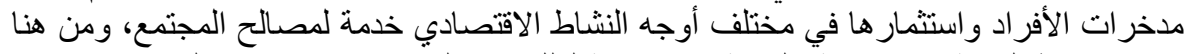

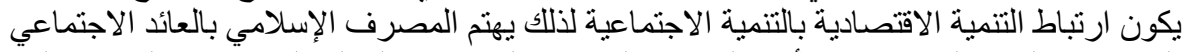

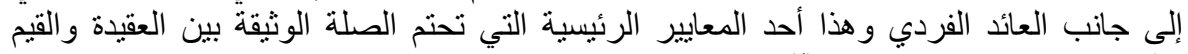

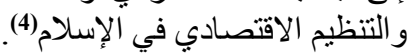
2- 2 أنواع المصارف الإسلامية :

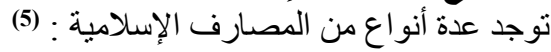

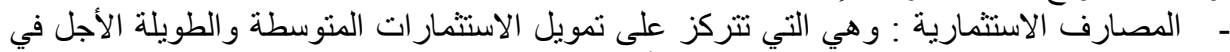

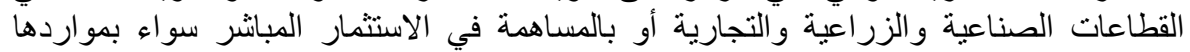
الخاصة أم بالمشاركة مع الآخرين. - المصارف الإنمائية ( التنموية) : وهي الآين التي تهتم بمجالات التنمية طويلة الددى كالاستثمار في مشرو عات البنى التحتية الأساسية للاولة.

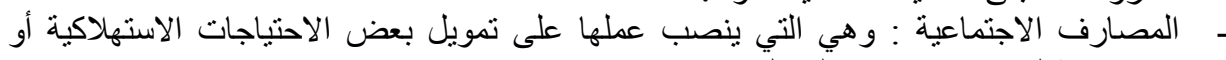
الاجتماعية لتساهم في تحقيق التكافل الاجنماعي. 
ـ ـ المصارف التجارية : وهي التي تقوم بتعبئة الموارد المالية من مصادر الفو ائض المالية ونوظيفها

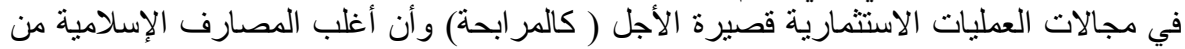

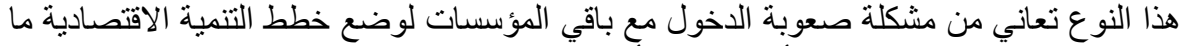
لم تعتمد على الاستثمار المنوسط أو الطويل الأجل.

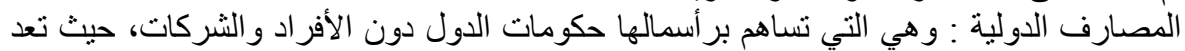

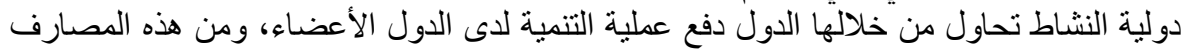

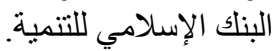

ــ المصارف المركزية: وتكون وظيفتها إصدار الأوراق المالية في الدولة والرقابة على الايتمان

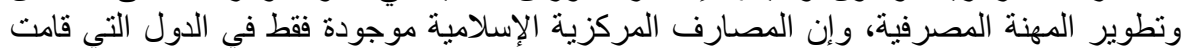

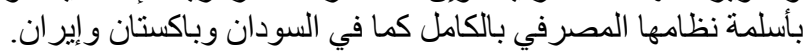
3- خصائص المنتجات المالية الإسلامية :

يمكن حصر أهم خواص الهنتجات المالية الإسلامية في المصدافية المالية الثرعية فهي الأساس في كونها

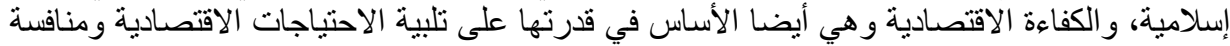

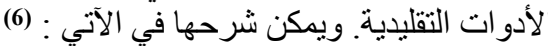

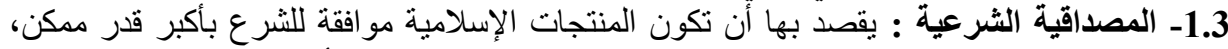

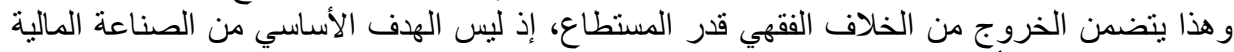

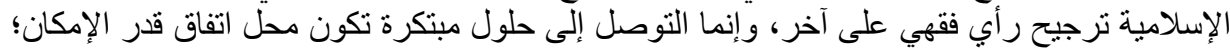

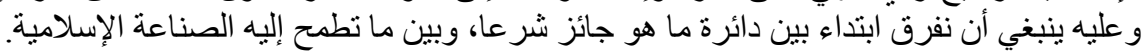

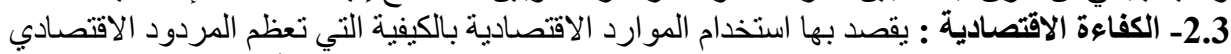

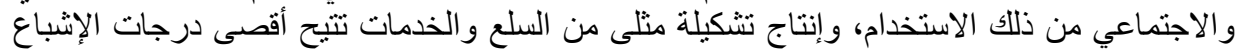

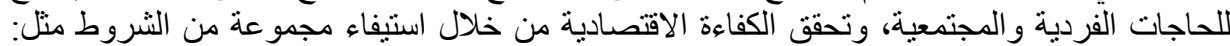

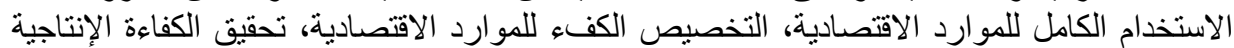

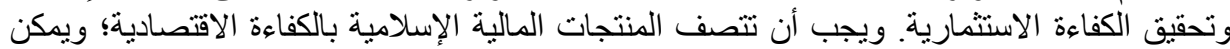

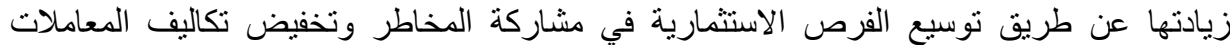

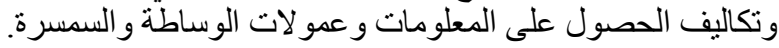

ثناتيا : الثقافة التنظيمية للمصارف الكمان

تمثل الكيفية التي تنظر فيها المؤسسة ككل إلى عملية نطوير المنتجات و الكيفية التي تتعامل فيها مع تلكي

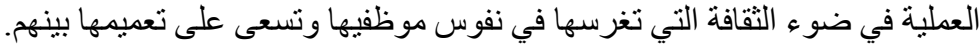
1- 1 مفهوم الثقافة التنظيمية :

تلخص الثقافة طريقة أداء الوظائف بالمؤسسات وتؤثر على أكثر القضايا أهمية في حباة المؤسسة

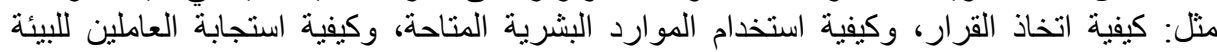

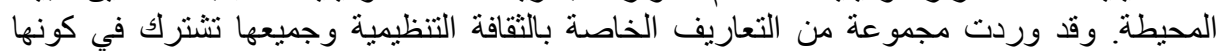
مجمو عة من القيم و المعتقدات و العادات و والتقاليد وسلوك التكان العاملين (7).

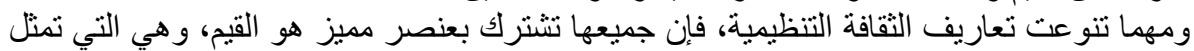

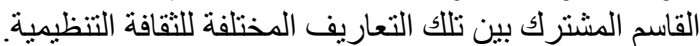

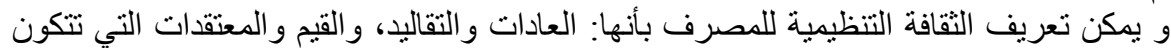

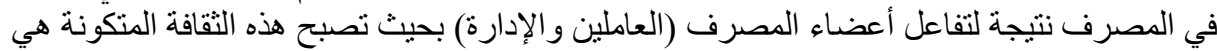

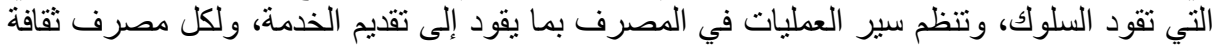

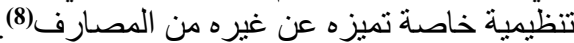
2- 2 - أهية الثقافة التنظيمية :

تلعب الثقافة التنظيمية دورا جوهريا في تنمية وتطوير المؤسسات فهي تمثل الأصل السلوكي في المؤسسة الذي يمكن من خلاله توقع الأحداث. كما تعتبر الثقافة التظظيمية المحرك الأساسي للطاقات 
والقدرات، فهي تؤثر بالدرجة الأولى على الأداء وتحقيق الإنتاجية المرتفعة نتيجة لاختيار الوسائل

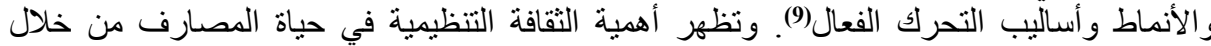

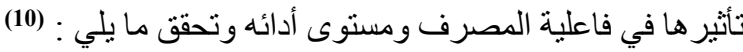

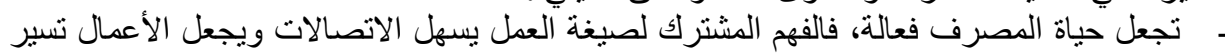

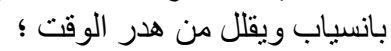

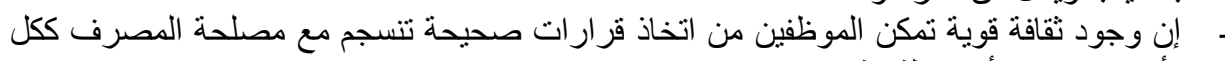

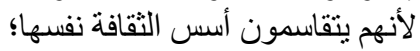

- - إن وجود ثقافة تنظيمية فعالة تنمي لأى جميع الموظفين الإحساس بالانتماء، وتساعد على استقرار

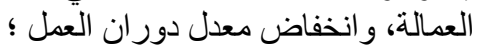

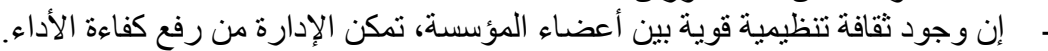
3- خصائص الثقافة التنظيمية :

إن خصائص الثقافة التنظيمية و التي تأخذ مستوى اهتمام عال ومنخفض وتتمثل في : (11)

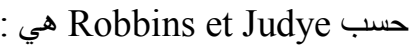

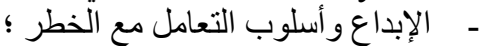
ــ ـ الالتمام بالتفاصيل : أي درجة توقع العاملين لضبط التفاصيل، وتحليلها و الانتباه إليها و الاهتمام بها - توجه النتيجة : أي درجة نركيز الإدارة على النتائج بدلا من الأساليب والعمليات المستخدمة

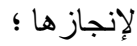
- - توجه الأفراد : أي الدرجة التي تتخذ فيها الإدارة قراراتها آخذة بالاعتبار ثأثثر النتائج على أفراد

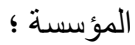

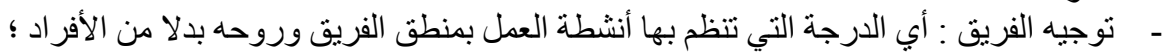

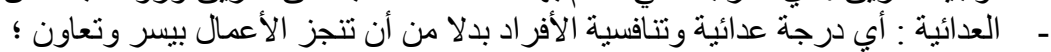

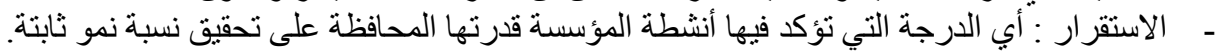

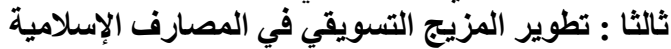

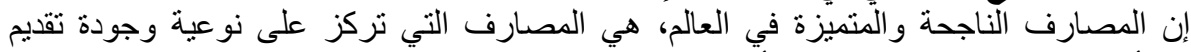

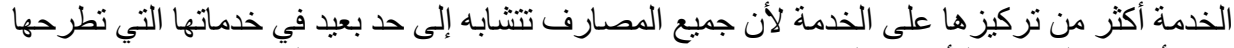

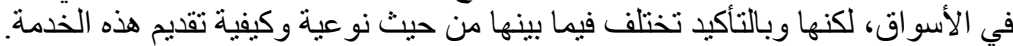

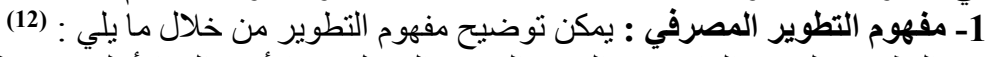

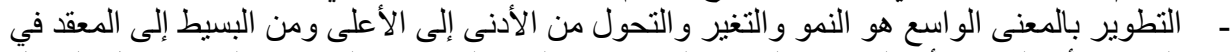

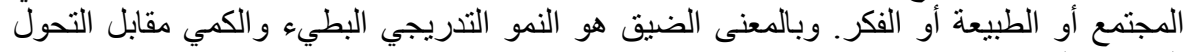

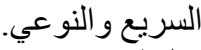
- ـ و التطوير هو إستر اتيجية التغيير وتحسين إدارة وتشغيل المؤسسة بهدف زيادة إنتاجيتها وزيادة العائد على الاستثمار. - ـ والتطوير هو مجموعة الأسس والمعايير الممكن إنباعها في سبيل تحسين نوعية وكفاءة الثيء الثيء

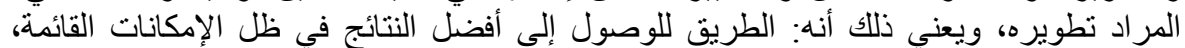

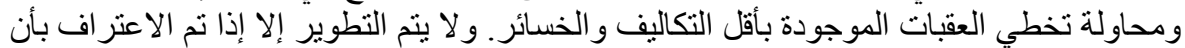

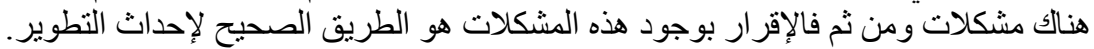

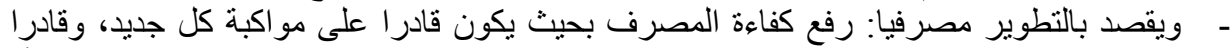

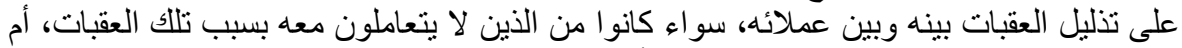

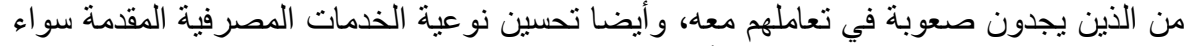

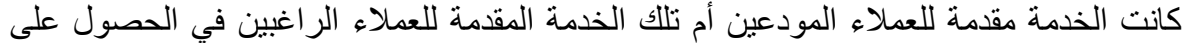
التمويل وفق طرق التمويل المختلفة. 
2- تعريف التسويق الإسلامي : بمكن تعريف التسويق المصرفي الإسلامي في المصارف الإسلامية

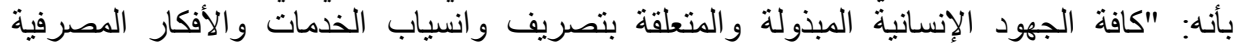

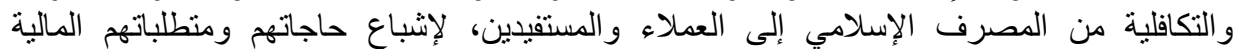

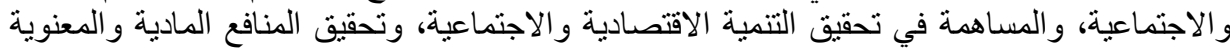

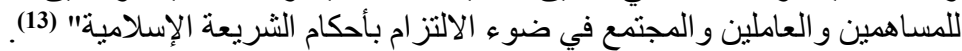

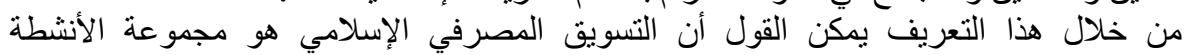

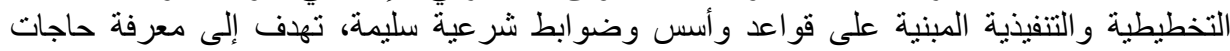

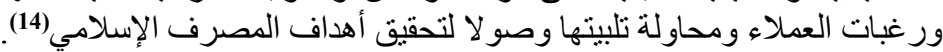

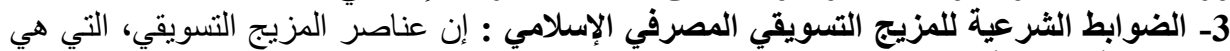

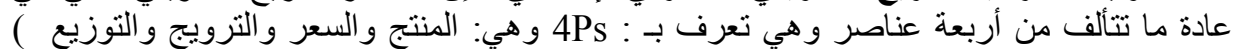

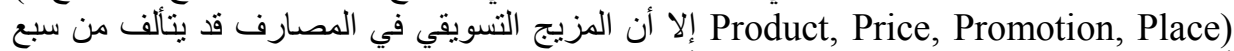

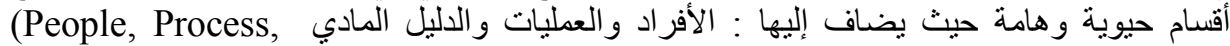

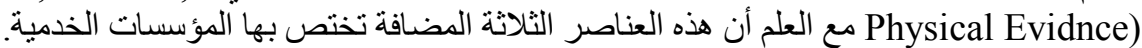

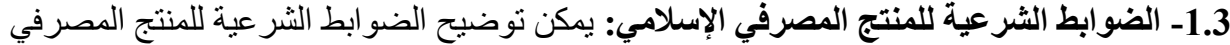

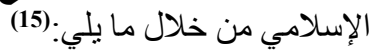
- رفض التعامل بالسلع والذذمات غير الحلال : وهذا من أبرز ما يميز المصارف الإسلامية عن



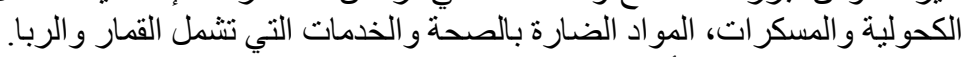

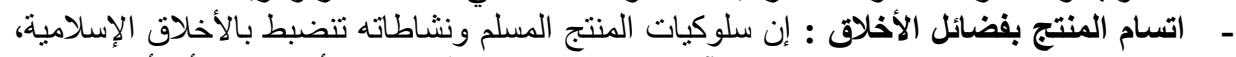

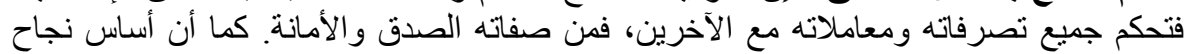

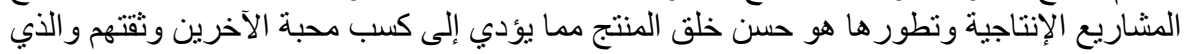

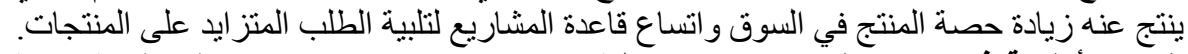

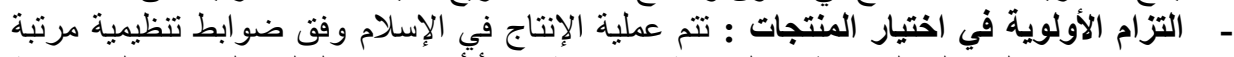

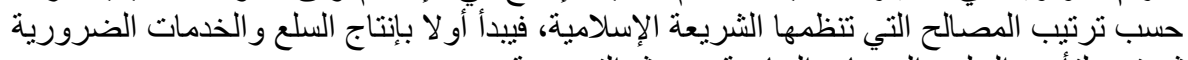

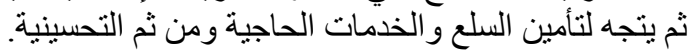

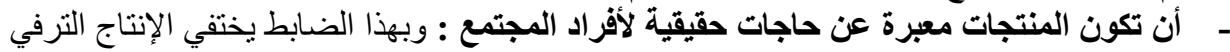

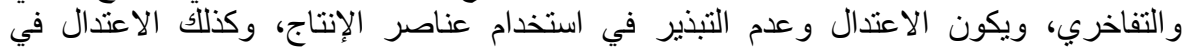

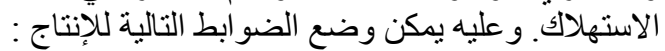

عدم جواز تقديم المنتج أو الخدمة المصرفية بلإنثاج بسر مرتفع وأعلى من سعر السوق منعا للغبن. عدم جواز استغلال المستهلكين حاجات المستهلكين لعدم إدر اكهم اللسلعة.

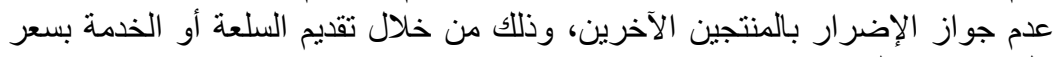
بقل عن سعر السوق.

لا يجوز التوقف عن إنتاج السلعة أو الخدمة إن كانت من السلع أو الخدمات الضرورية للاجتمع ولم يكن لها بديل في الأسواق.

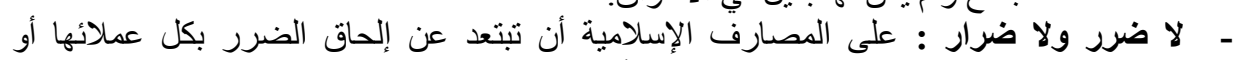

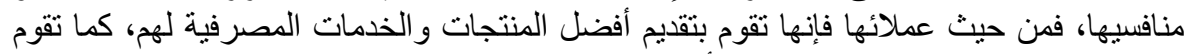

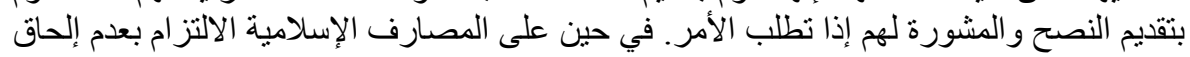

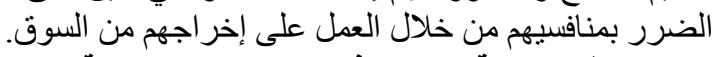

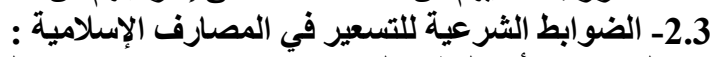

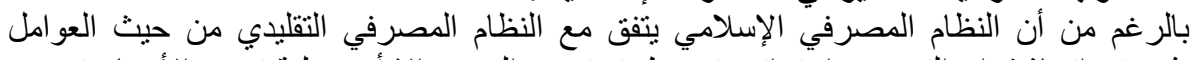

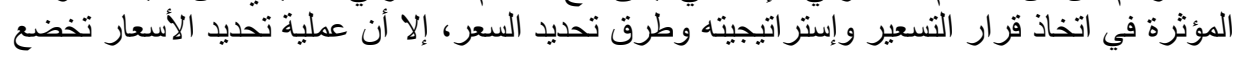


إلى مجموعة من الضوابط و الأحكام الثرعية، وبما يخدم تحقيق مصلحة البائع و المستهلك و المجتمع

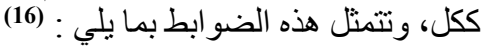

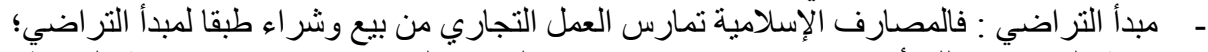

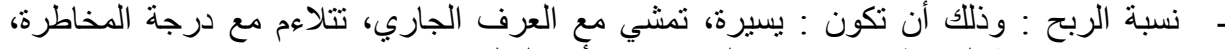

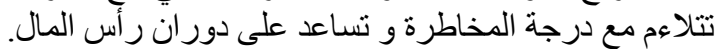

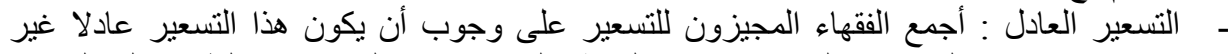

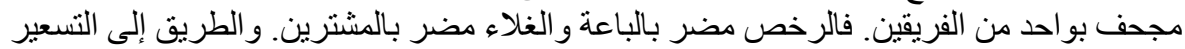

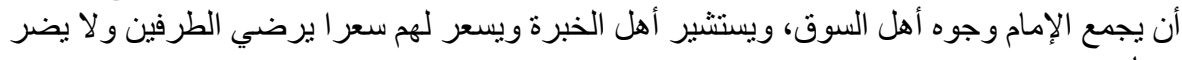
3.3- الضوابط الثرعية للتوزيع في المصارف الإسلامية : يمكن توضيح الضوابط الثرعية للتوزيع

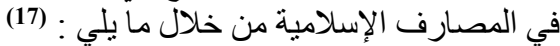

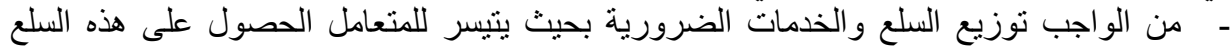

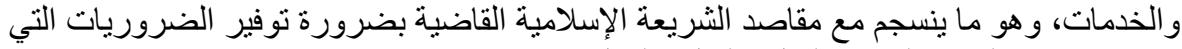

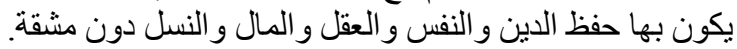

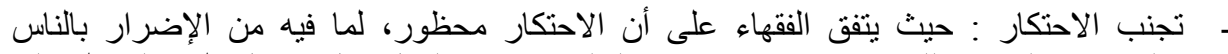

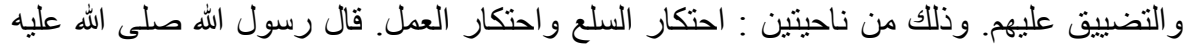

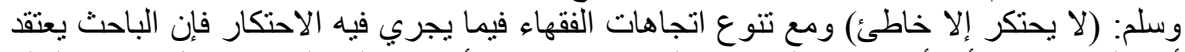

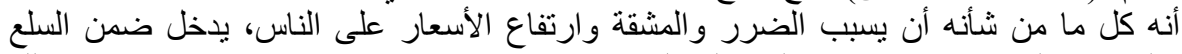

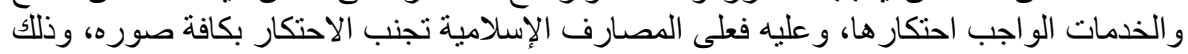

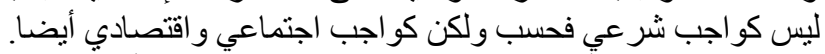

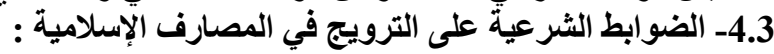

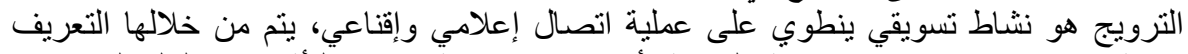

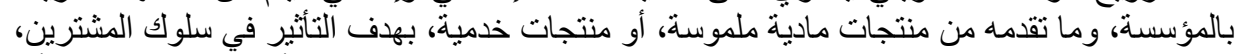

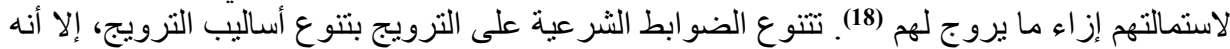

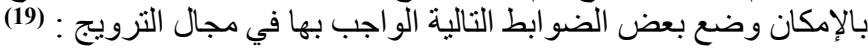
- الابتعاد عن :

التدليس : وهو : وهتمان عيب السلعة عن المشتري.

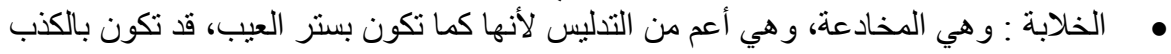
وغيره.

• التلبيس : و هو اختلاط الأمر. وقد يكون بإخفاء صفات أو وقائع أو غير ها ليست صحيحة.

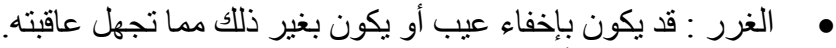

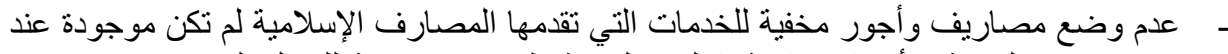

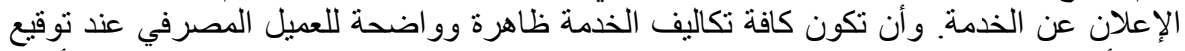
العقد أو تقديم الخدمة. والابتعاد عن الإعلان عن نكلفة ظاهرة لخدمة معينة وهي في الحقيقة أعلى الحي موا هو معلن عنه. ـ - توخي الصدق و الأمانة في التعريف بالمنتج المصرفي: وهذا من أبسط منطلبات بناء الثقة بين

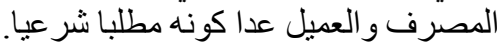

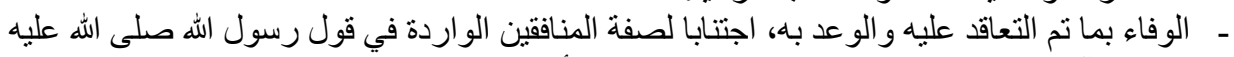

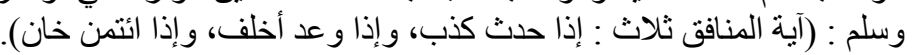

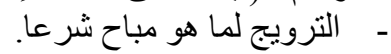
- - استخدام وسائل ووسائط الترويج المباحة شرعا، واءئ والابتعاد قدر المستطاع عن طرق الترويج التي تختلف حولها الآر اء الثر عية. 


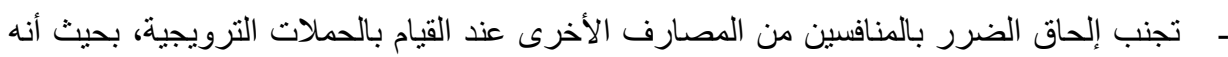

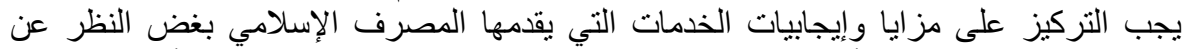

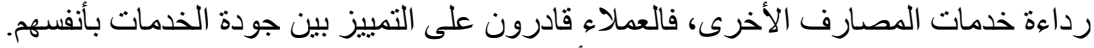

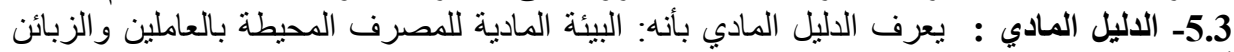

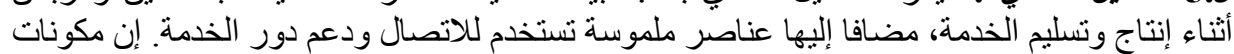

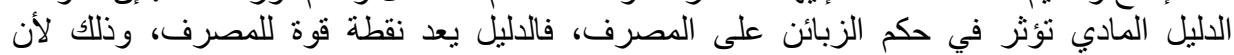

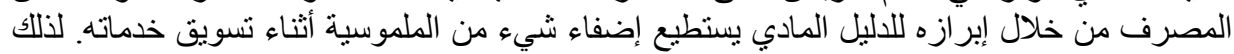

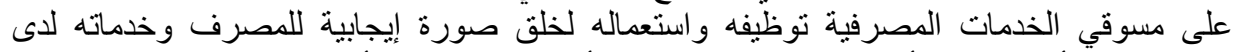

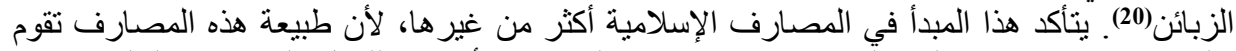

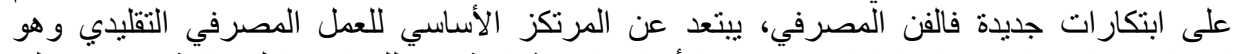

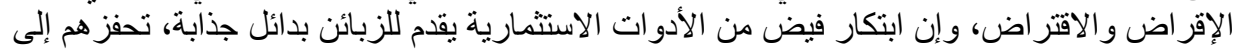

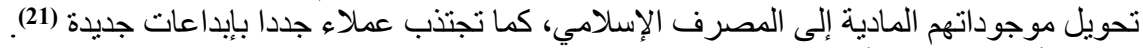

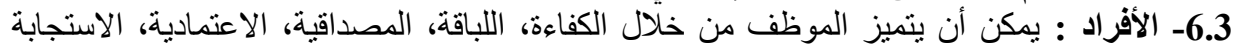

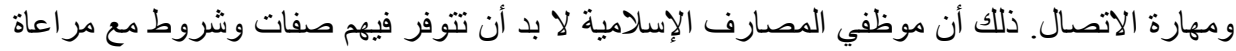

خصوصية عمل كل موظف، ومنها نذان الذكر : (22)

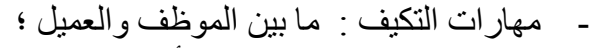

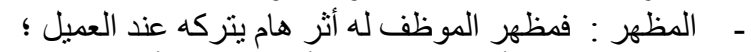

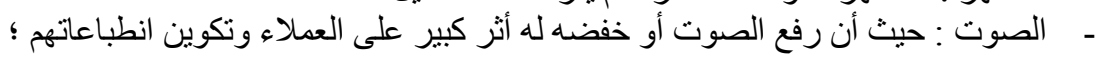

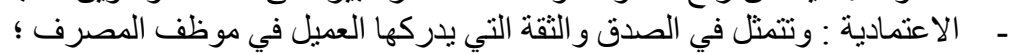

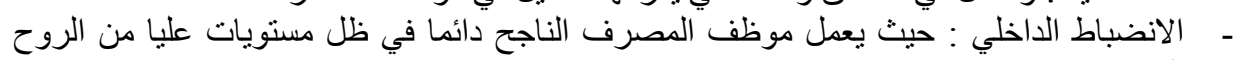

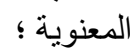

ـ الاستعداد للاستماع (الإصغاء) : وهذا يعطي الانطباع بدرجة اهتمام الموظف بالعميل ووجهة

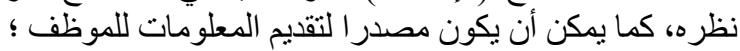

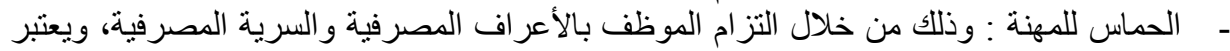

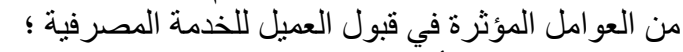

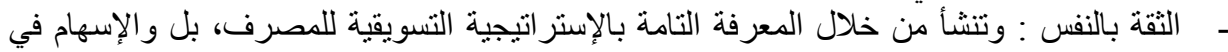

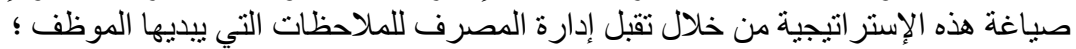
- الملاحظة : وتتمثل في مقدرة الموظف على ملاحظة كل ما يبديه العميل من آراء و أفكار وحتى لئى

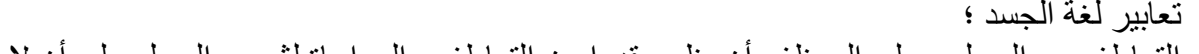

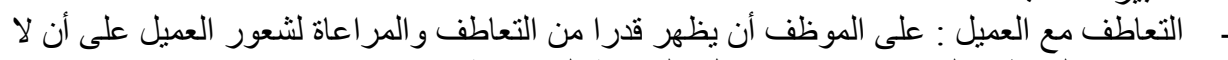

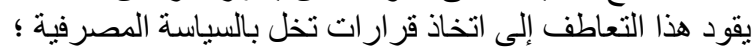

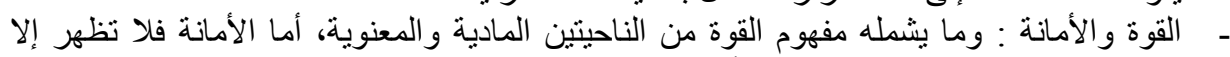

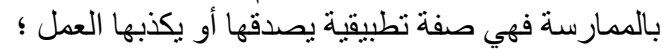

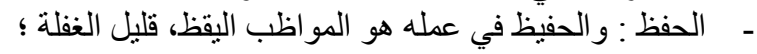
-

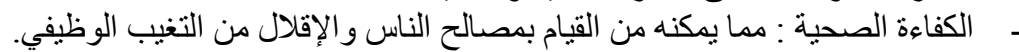

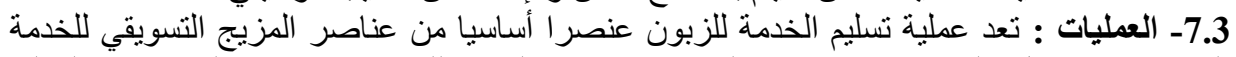

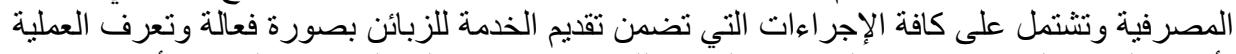

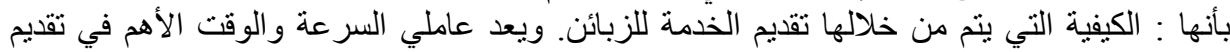

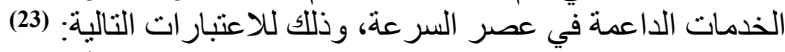

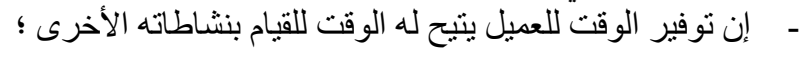


- إن سرعة إنجاز المعاملة المصرفية للعميل التاجر تنشكل له فرصا لتحقيق الأرباح من خلال

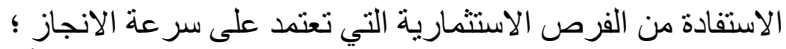

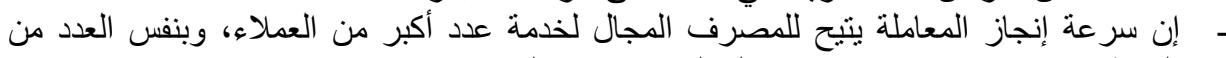

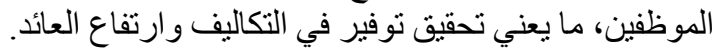

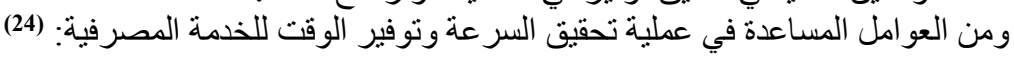

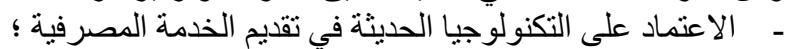
- - اختصار إجراءات العمليات المصرفية و البعد عن الروتين و البيروقر اطية ؛

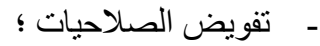

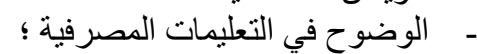

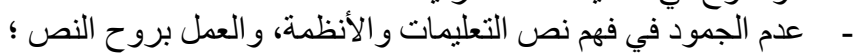

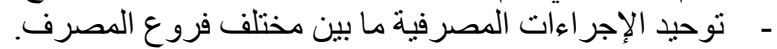

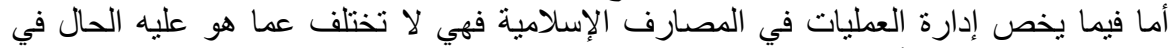

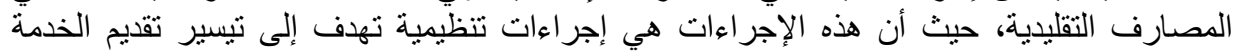

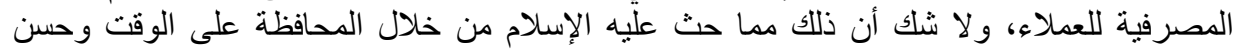

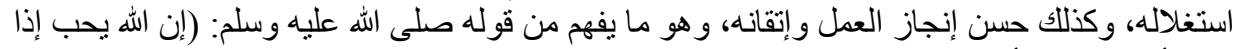
عمل أحدكم عملا أن يتقنه) فمفهوم إتقان العمل يشمل جودة الخدمة المقدمة وكذللك سرعة الانجاز و وعدم إضماعة الوقت و هدره(25). خاتمة :

بحتل التسويق مكانة هامة داخل مختلف المؤسسات ومنها المصارف، فهو بعد وظيفة بالغة الأهية

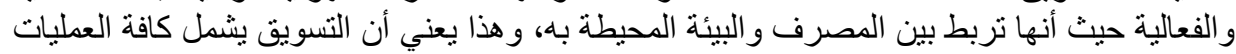

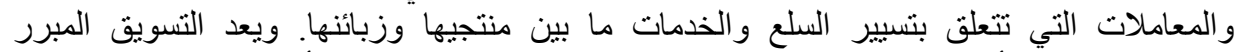

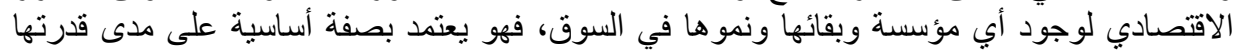

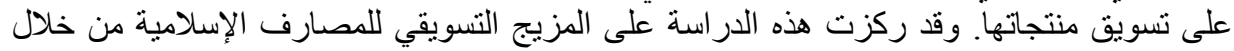

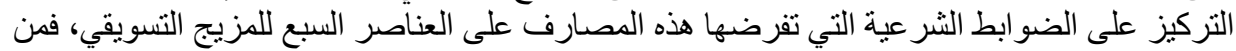

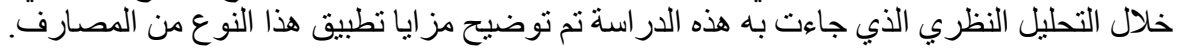

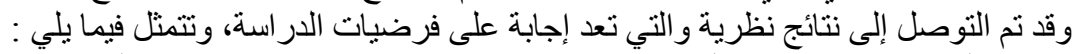

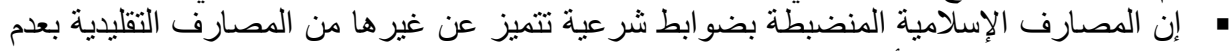

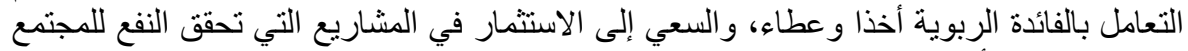

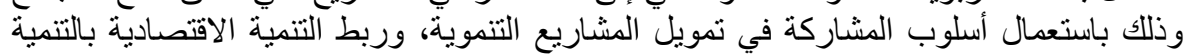

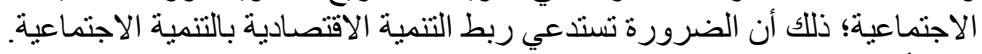

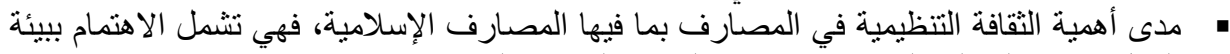

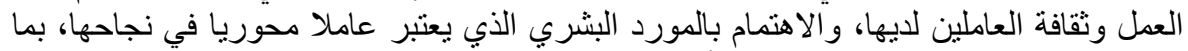

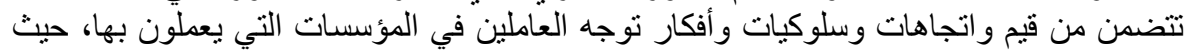

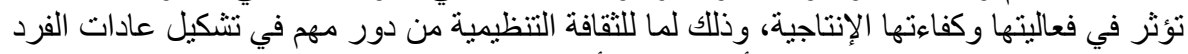

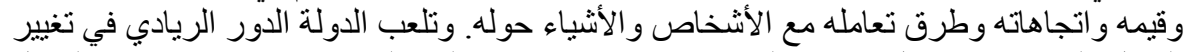

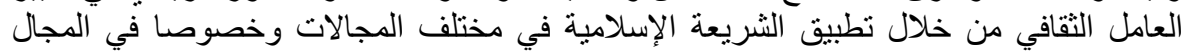

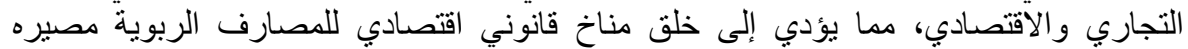
الزو ال، لأن البنك المركزي سوف تتحول قو انينه بحيث تكون منطابقة مع الثريعة الإسلامية فيخدم لإنية

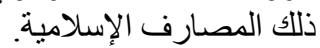

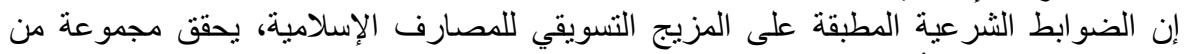
الميزات يمكن حصر أهمها في الآتي: 


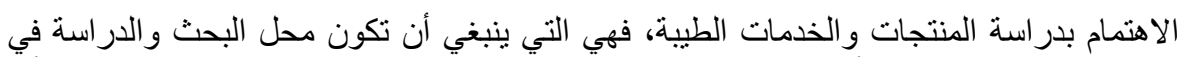

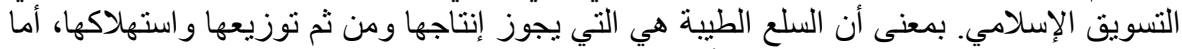

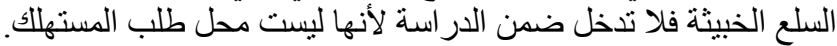

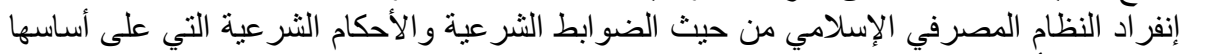

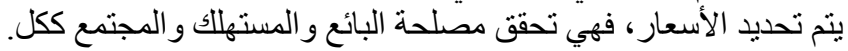

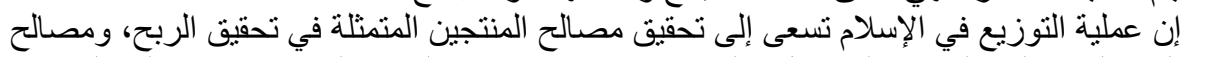

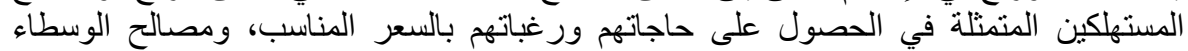
المنتلة في الحصول على عائد مقابل النشاط المبذول في العملية التبادلية بين الطرفين المنتج والمستنالكي.

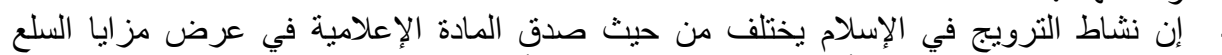

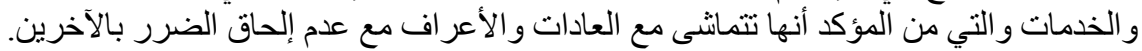

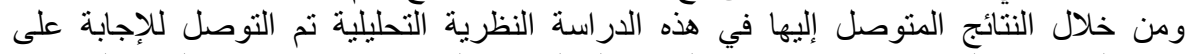

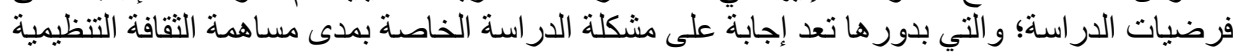

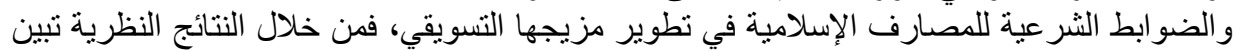
أنه فعلا لهذه الضوابط الثرعية دور كبير وواضئ فئح في تطوير المزيج التسويقي إضافة إلى خلق بيئة تنافسية قائمة على مبادئ سليمة وصحية.

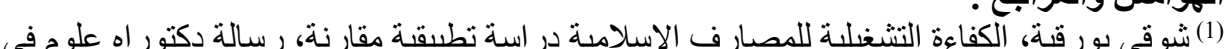

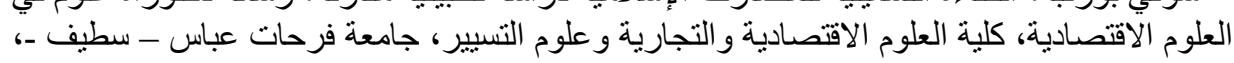

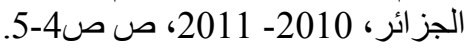

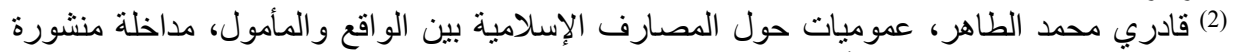

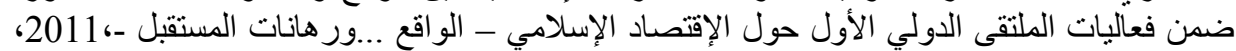

Iefpedia.com/arab/wp-content/uploads/2011/03/pdf.

$$
\text { ص 10. تم الاطلاع عليه على الموقع: }
$$

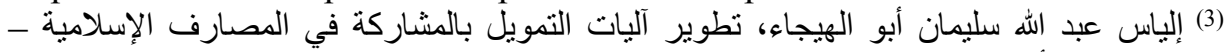

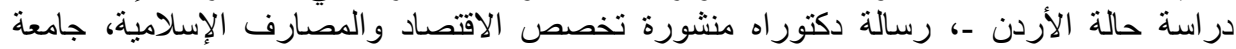
اليرموك، أربد، الأردن، 2007، ص صن 16-17. نم الاطلاع عليه على الموقع: .www.Kantakji.com/media/2286/b094.pdf

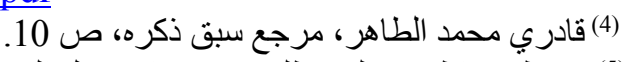

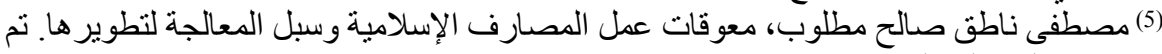

$$
\begin{aligned}
& \text { الاطلاع عليه على الموقع: }
\end{aligned}
$$

.www.iasj.net/iasj?Func $=$ Fulltexxt\&aId $=61016$

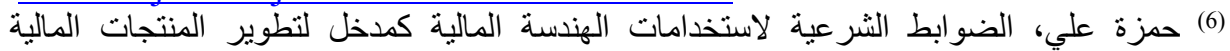
الإسلامية، مداخلة منشورة ضمن فعالية الطيات الملتقى الدولي الثاني للصناعة المالية الإسلامية. تم الاطلاع

Iefpedia.com/arab/wp-content/uploads/2013/12/pdf.

$$
\text { عليه على الموقع: - ملن }
$$

(7) موسى اللوزي، التنظيم واجر اءات العمل، ط2، دار و ائل للنشر، عمان، الأردن، 2007، ص ص

(8) لمى فيصل إسبر، مدخل مقترح لرفع الكفاءة والفعالية المصرفية من منظور إدارة الجودة الثناملة -

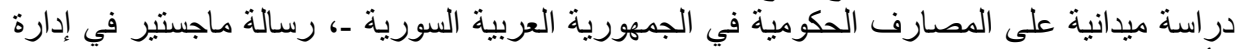
الأعمال منشورة، كلية الاقتصاد، جامعة تشرين، 2009، ص الجية 80. تم الاطلاع عليه على الموقع: 
www.tishreen.edu.sy/sites/default/files/research_letter/Facultyof Economics

Master's thesis 2009 2.pdf

(9) يوسف مسعداوي، أساسيات في إدارة المؤسسات، دار هومة للطباعة والنشر والتوزيع، الجزائر،

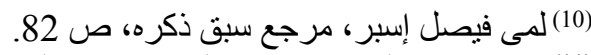

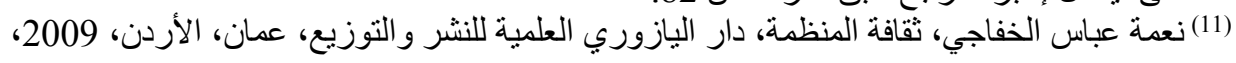

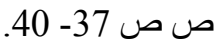

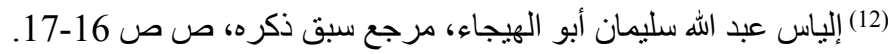

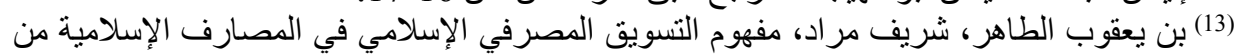

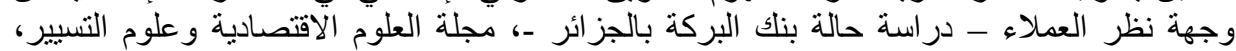
جامعة سطيف، العدد 13، 13-2013 2013، ص 145. 145. تم الاطلاع عليه على الموقع: .www.univ-ecosetif.com/revueeco/cahiers_Fichiers/revue-13-2013/005.pdf

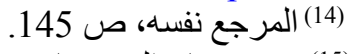

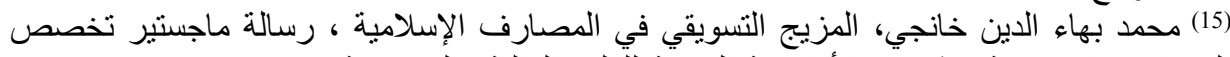

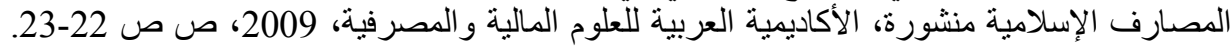

www.Kantakji.com/media/1616/90069.pdf تم الاطلاع عليه على الموقع: منتورة

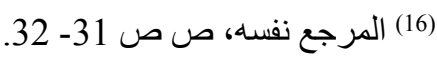

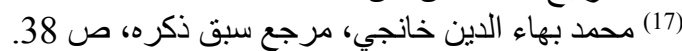

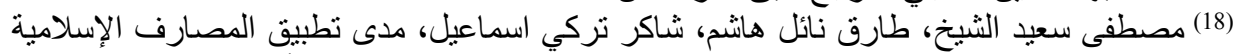

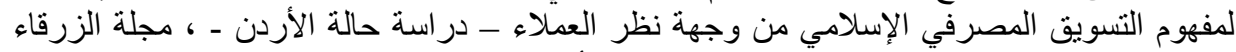
للبحوث والدراسات الإنسانية، المجلّ التاسع، العدد الأول، 2009، ص 111. تم الاطلاع عليه على الأى

Zujournal.org/ar/images/stories/2011/1-2009/5.pdf.

الموقع:

$$
\begin{aligned}
& \text { (19) محمد بهاء الدين خانجي، مرجع سبق ذكره، ص ص 5 55- 56. } 56 .
\end{aligned}
$$

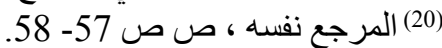

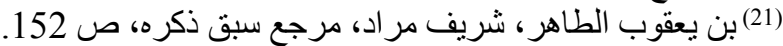

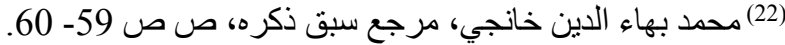

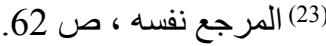

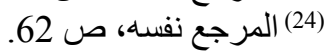

$$
\begin{aligned}
& \text { (25) (المرجع نفسه، ص صنس، صن } 64 .
\end{aligned}
$$

